\title{
Pericardial Tamponade during Supra Hepatic IVC Angioplasty in Budd-Chiari Syndrome Managed by Ultrasound-Guided Pericardiocentesis
}

\author{
Alex Ajay ${ }^{1}$ Valakkada Jineesh ${ }^{1}{ }^{\circledR}$ Ayyappan Anoop ${ }^{1}$ Santhosh Kannath ${ }^{1}$ Harshit Kramadhari $^{1}$ \\ ${ }^{1}$ Department of Imaging sciences and Interventional Radiology, Sree \\ Chitra Tirunal Institute for Medical Sciences and Technology, \\ Thiruvananthapuram, Kerala, India \\ Address for correspondence Valakkada jineesh, MBBS, MD, Sree \\ Chitra Tirunal Institute for Medical Sciences and Technology, \\ Thiruvananthapuram 695011, Kerala, India \\ (e-mail: jineesh174@gmail.com).
}

J Clin Interv Radiol ISVIR 2022;6:223-225.

\section{Introduction}

Role of endovascular interventions has increased in the treatment of inferior vena cava (IVC) occlusion including Budd-Chiari syndrome, since surgical options are limited. Fibrous component in thrombus, anatomical narrowing of IVC, the ambiguity of course of IVC to the atrium, and inability to assess across occlusion are all challenges faced in interventions in Budd-Chiari syndrome. ${ }^{1}$ The occurrence of iatrogenic cardiac tamponade is a rare complication of IVC venoplasty. ${ }^{1,2}$ Herein, we present a case that highlights the importance of timely anticipation of this near-fatal event and management of pericardial tamponade in salvaging the patient's life.

\section{Case Report}

A 33-year-old gentleman presented with bilateral varicose veins, dilated abdominal wall veins, and delayed healing ulcers on the left side for the past 10 years. Ultrasonography revealed complete occlusion in the supra hepatic IVC. Magnetic resonance imaging revealed hepatomegaly and confirmed the occlusion for $1.8 \mathrm{~cm}$ (-Fig. 1A). The patient was taken up for IVC venoplasty through the right common femoral vein and right internal jugular vein venous accesses. Venogram confirmed occlusion of the IVC with flow via collaterals into the superior vena cava and right atria (RA) in the delayed phase (-Fig. 2). The occlusion was crossed using 0.035 " wire using a 7F long sheath and a 5F support catheter. The distal end of the catheter was confirmed to be within the RA by contrast injection. The wire was exchanged

for a 0.035 " stiff wire and venoplasty was initially done using $4 \times 20 \mathrm{~mm}$ (diameter $\mathrm{x}$ length) balloon. Further, venoplasty was done using a $10 \times 40 \mathrm{~mm}$ balloon. The patient developed sudden dyspnea and chest pain with a fall in blood pressure to $60 / 30 \mathrm{~mm} \mathrm{Hg}$. Electrocardiogram showed sudden drop in QRS voltages in all leads. Immediate ultrasonography showed large pericardial hemorrhage with tamponade. Emergency pericardiocentesis was done under ultrasound guidance with two $16 \mathrm{G}$ needles placed from the left para cardiac region, which drained $\sim 200$ to $250 \mathrm{~mL}$ of blood. Heparin reversal with protamine $(25 \mathrm{mg}$ given as $5000 \mathrm{U}$ heparin was given around 90 minutes prior to the event) was done and $10 \times 40 \mathrm{~mm}$ balloon was kept partially inflated across the cavoatrial junction to prevent further hemorrhage. The patient was intubated and hemodynamically stabilized. The balloon was kept partially inflated for 30 minutes, until the venogram showed no residual leak. The patient was extubated on the same day. Postoperative day 1 ultrasound showed improved flow across the supra hepatic IVC with and no residual hemorrhage.

\section{Discussion}

The incidence of pericardial tamponade is not uncommon with incidences of 0.75 to $0.99 \%$ in cases undergoing IVC venoplasty for Budd-Chiari syndrome. ${ }^{1,2}$ The endovascular procedure with highest incidence of pericardial hemorrhage includes IVC filter with strut fracture/migration. ${ }^{3}$ Other causes excluding intracardiac/coronary procedures include mediastinal biopsies, ${ }^{4}$ aortic stent-graft placement, ${ }^{5}$ and

DOI https://doi.org/ 10.1055/s-0041-1742230. ISSN 2457-0214. (c) 2022. Indian Society of Vascular and Interventional Radiology. All rights reserved.

This is an open access article published by Thieme under the terms of the Creative Commons Attribution-NonDerivative-NonCommercial-License, permitting copying and reproduction so long as the original work is given appropriate credit. Contents may not be used for commercial purposes, or adapted, remixed, transformed or built upon. (https://creativecommons.org/ licenses/by-nc-nd/4.0/)

Thieme Medical and Scientific Publishers Pvt. Ltd., A-12, 2nd Floor, Sector 2, Noida-201301 UP, India 


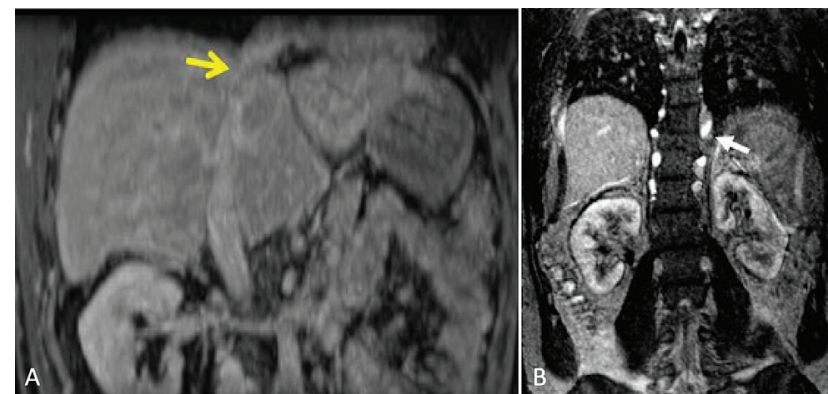

Fig. 1 (A) Magnetic resonance (MR) postcontrast coronal images showing narrowing of the distal hepatic inferior vena cava (IVC) and supra hepatic IVC (yellow arrow) showing near-complete occlusion. (B) MR coronal images showing prominent lumbar venous collaterals (white arrow) there were seen draining via prominent azygous and hemizygous veins (not shown in the figure) into superior vena cava.

central venous port insertion. ${ }^{6}$ IVC-RA junction is in close relation with the pericardium that forms a recess around the vena cava. ${ }^{7}$ The nature of the obstruction in Budd-Chiari syndrome may require high inflation pressures. Situations wherein there is higher risk of pericardial hemorrhage during IVC venoplasty include cases of left hepatic vein obstruction, left hepatic vein/middle hepatic vein) complex involvement, and use of sharp needles to negotiate the occlusion. The former is due to the anatomical configuration of the left hepatic vein being closer to the pericardium than the right hepatic vein. ${ }^{8}$ In our case, we presume leak to have occurred due to tear at the time of balloon dilation at the fibrotic occlusion site as no leak was detected in intervening venograms after initial wire passage or dilation.

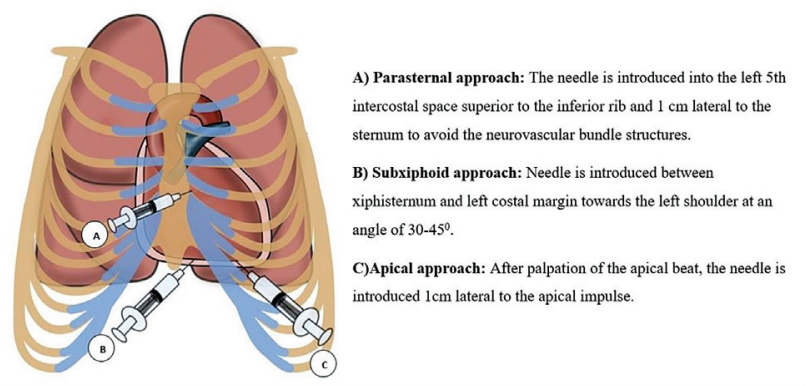

Fig. 3 Summary of the various approaches for pericardiocentesis: (A) Parasternal, (B) subxiphoid, and (C) apical approach.

Pericardiocentesis is a lifesaving in cases of pericardial tamponade. ${ }^{9}$ Three approaches for performing pericardiocentesis include subxiphoid, parasternal, and apical approaches (- Fig. 3).$^{10}$ When done under ultrasound guidance, the needle is directed into the deepest pocket of hemorrhage avoiding intervening structures. Slight reverse Trendelenburg positioning may improve the visualization. The subxiphoid approach is the safest approach in unguided insertion. ${ }^{11}$ The parasternal approach has risk of pneumothorax and apical approach of left ventricular puncture. ${ }^{10}$

A guidewire is introduced through the needle followed by pigtail catheter insertion for prolonged drainage. Also, the catheter can be connected back into a peripheral venous cannula as in autotransfusion with risks of thrombus and disseminated intravascular coagulation. ${ }^{12}$ Surgical pericardial window may be created if not responding to catheter drainage. $^{9}$

Hence, interventionalists should be aware of cardiac tamponade that may occur in procedures involving the

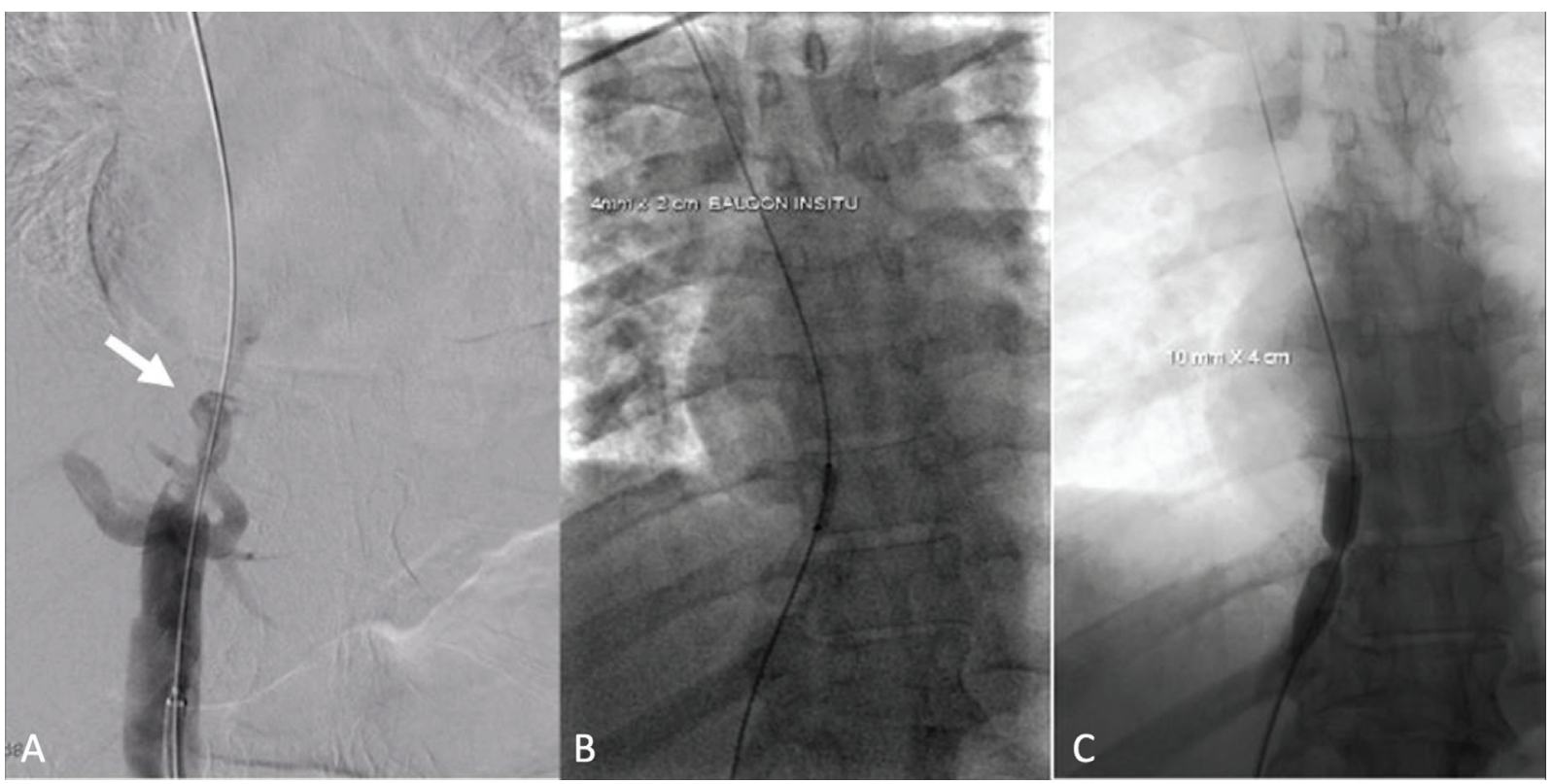

Fig. 2 Digital subtraction angiogram showing near-complete occlusion in the region of supra hepatic inferior vena cava (arrow in A) with faint contrast flow noted into the RA. Initially, venoplasty was done using $4 \times 2 \mathrm{~mm}$ balloon (B) followed by $10 \times 4 \mathrm{~mm}$ (C). 
cavoatrial junction and performing pericardiocentesis in such situations as an immediate standard bailout procedure since the time to act is very less.

\section{Authors' Contributions}

All the authors have contributed for data collection, design, and manuscript preparation.

\section{Conflicts of Interest}

None declared.

\section{References}

1 Zhang QQ Xu H, Zu MH, et al. Strategy and long-term outcomes of endovascular treatment for Budd-Chiari syndrome complicated by inferior vena caval thrombosis. Eur J Vasc Endovasc Surg 2014; 47(05):550-557

2 Wei X, Hao X, Da-Hai Y, Mao-Heng Z, Qing-Qiao Z, Yu-Ming G. Analysis of interventional treatments of Budd-Chiari syndrome and the related complications: a study of 1006 cases. Panminerva Med 2013;55(04):371-376

3 Bikdeli B, et al. 'Hemopericardium and Cardiac Tamponade as a Complication of Vena Caval Filters: Systematic Review of the Published Literature and the MAUDE Database', Clinical and applied thrombosis/hemostasis: official journal of the Interna- tional Academy of Clinical and Applied Thrombosis/Hemostasis. , vol. 25, pp. 1076029619849111-1076029619849111, 2019 Doi: $10.1177 / 1076029619849111$

4 Harmon TS, Wynn G, Meyer TE, Siragusa D, Matteo J. Complicated complication: how interventional radiologists should manage acute iatrogenic cardiac tamponade. Cureus 2018;10(12): e3708-e3708

5 Haller I, Lederer W, Stichlberger M, et al. Iatrogenic cardiac tamponade during endovascular aortic and mesenteric stent grafting: a case report. A A Case Rep 2017;8(06):142-144

6 Machat S, Eisenhuber E, Pfarl G, et al. Complications of central venous port systems: a pictorial review. Insights Imaging 2019;10 (01):86. Doi: 10.1186/s13244-019-0770-2

7 Levy-Ravetch M, Auh YH, Rubenstein WAet al Ravetch. CT of the pericardial recesses. AJR Am J Roentgenol 1985;144(04):707-714

8 Ger R. Surgical anatomy of the liver. Surg Clin North Am 1989;69 (02):179-192

9 Adler Y, Charron P, Imazio M, et al. 2015 ESC guidelines for the diagnosis and management of pericardial diseases. Rev Esp Cardiol (Engl Ed) 2015;68(12):1126. Doi: 10.1016/j. rec.2015.10.008

10 Kumar R, Sinha A, Lin MJ, et al. Complications of pericardiocentesis: A clinical synopsis. Int J Crit Illn Inj Sci 2015;5(03):206-212

11 Krikorian JG, Hancock EW. Pericardiocentesis. Am J Med 1978;65 (05):808-814

12 Morton AC, Gunn J. A case of autotransfusion from pericardium to femoral vein. Heart 2006;92(12):1727. Doi: 10.1136/hrt.2006.088823 